\title{
Using Facebook Live to Enhance the Reach of Nutrition Education Programs
}

\author{
Omolola A. Adedokun, PhD; Marisa Aull, BS; Paula Plonski, MA; Denise Rennekamp, MS; \\ Katie Shoultz, JD; Michele West, MS
}

\section{INTRODUCTION}

This Great Educational Materials article describes the University of Kentucky Nutrition Education Program (KYNEP) delivery of Healthy Choices for Every Body (HCEB), a nutrition education curriculum, through Facebook Live (Facebook, Inc, Menlo Park, CA) to extend the reach of nutrition education to low-income adults who face barriers in participating in face-toface nutrition education classes. The purpose of this article was 2-fold: to demonstrate how to use Facebook Live to deliver a standard nutrition education program to low-income audiences, and to illustrate potential similar learning outcomes between in-person and Facebook Live delivery methods of the same nutrition education content.

\section{PROGRAM IMPLEMENTATION}

Facebook Live

Facebook Live is a real-time online live streaming function of Facebook (Facebook, Inc) that allows users to broadcast live content. ${ }^{1}$ Facebook Live is both synchronous and asynchronous. The platform automatically creates video recordings of live broadcasts that can be posted to the presenter's page and/or shared with other users after the live streaming event. Facebook Live allows users to stream live video to a Facebook page or Facebook group. Creating and streaming to a private group allows users to control who is viewing and interacting with the content. The capability for interaction is a key benefit of the Facebook Live platform. $^{2,3}$ Facebook Live has a comment section that facilitates interactivity between presenters and their viewers and among viewers. Comments can be in the form of text, photographs, graphics interchange format, or emoji.

\section{Curriculum Delivery}

The KYNEP uses HCEB, ${ }^{4}$ a researchtested adult nutrition education curriculum available in the national Supplemental Nutrition Assistance Program Education (SNAP-Ed) toolkit, to provide nutrition education to lowincome audiences. Both the face-toface and Facebook Live delivery approaches incorporated HCEB curriculum components but with 2 major differences. First, only the final class of Facebook Live was face-to-face. This final class offered participants the opportunity to collect lesson reinforcement items/incentives, participate in a face-to-face food demonstration and tasting, and complete postimplementation evaluation instruments. Second, the 2 approaches differed in the evaluation of data collection strategies. Data collection for the traditional approach was entirely paper-based; however, participants in the Facebook Live approach

\footnotetext{
Nutrition Education Program, University of Kentucky, Lexington, KY

Conflict of Interest Disclosure: The authors have not stated any conflicts of interest.

Address for correspondence: Omolola A. Adedokun, PhD, Nutrition Education Program, University of Kentucky, 1500 Bull Lea Rd, Ste 130, Lexington, KY 40511; E-mail:

Lola.adedokun@uky.edu

J Nutr Educ Behav. 2020;52:1073-1076

(C) 2020 Society for Nutrition Education and Behavior. Published by Elsevier Inc. All rights reserved.

https://doi.org/10.1016/j.jneb.2020.08.005
}

provided evaluation data through Qualtrics and/or paper-based methods.

A typical Facebook Live session began with a welcome message, an overview of the session lesson, and an icebreaker. Icebreakers were modified to fit the online delivery format better. Questions or games to which participants could easily comment or respond were used. If there was little to no response from participants, the educator provided the correct response(s) and briefly discussed them. The content of the lesson was taught, and a food demonstration was presented. Questions for engagement (intended for participant comments) were asked throughout the session. The recipe for the specific lesson was posted to the group afterward, as was a session recording. Before going live, the nutrition educator sent a reminder message about the session and posted any handout materials needed for the specific lesson.

\section{Training and Implementation} Guidelines

Beyond its capacity for interaction, Facebook Live is free and easy to use. ${ }^{2}$ To record a Facebook Live curriculum delivery session, all the educators needed was to download the Facebook app to an iOS (Apple, Inc, Cupertino, CA) or Android (Google, LLC, Mountain View, CA) device. The addition of some minimal equipment such as a microphone, tripod, and lighting also enhanced the quality of the session. To watch a video was even more accessible. Participants only needed a Facebook account and an Internet connection strong enough to support streaming.

To support curriculum delivery by means of Facebook Live, KYNEP provided a required half-day, in-person training that covered implementation 
guidelines, policies, strategies for effective online presentations, the logistics and management of Facebook pages and groups, strategies for adapting curriculum delivery for online audiences, and equipment overview. Training and support also included discussion of materials and marketing resources, monitoring of broadcasts, procurement of technology/equipment on a county by county basis, and ongoing assistance throughout the implementation as needed. In addition to training, the KYNEP also provided educators with implementation support documents (Supplementary Data).

\section{Outcome Evaluation}

An outcome study examined if prepost gains in food resource management practices (FRM) and diet quality differed between participants in faceto-face vs Facebook Live classes taught in 2019. At that time, 4 nutrition educators delivered HCEB by means of Facebook Live to program participants $(\mathrm{n}=46)$, and also taught participants $(n=193)$ in regular face-to-face classes during the same period.

Educators recruited participants through traditional recruitment efforts (in-person contacts and referrals), in addition to social media channels. Educators were encouraged to recruit through posts to a KYNEP Facebook page created for the specific county and with a customizable KYNEP promotional flyer that was provided. Table 1 presents the demographic and educational characteristics of the groups.

Participants in both groups completed the food and physical activity questionnaire $^{5}$ and a 24-hour food recall $^{6}$ at program entry and exit, after which nutrition educators entered their data into the Webbased Nutrition Education Evaluation and Reporting System. ${ }^{7}$ Food resource management was measured as a summated rating scale consisting of 4 items on the food and physical activity questionnaire (eg, planning meals before shopping and comparing prices while shopping) with Cronbach $\alpha$ of $0.88 .^{8}$ Diet quality was measured by participants' Healthy Eating Index (2010) ${ }^{9}$ calculated from their 24-hour food recall. Web-based Nutrition Education Evaluation and Reporting System has an inbuilt algorithm that calculates healthy eating scores from participants' 24-hour food recall.

Chi-square tests of independence were conducted to compare demographic and educational characteristics between participants in Facebook Live and face-to-face groups. Food resource management skills and diet quality gain scores were calculated by subtracting baseline scores from exit scores (for example, FRM gain score $=$ FRM exit score - FRM entry score), and ANCOVA models were tested to compare FRM and diet quality gain scores between the 2 groups. Because participants were not randomly assigned to groups, baseline scores (and interactions between baseline scores and delivery approach) were included as control variables in the ANCOVA models. Given the observed statistically significant group differences in age,

Table 1. Demographic and Educational Characteristics of Facebook Live Participants $(n=46)$ and In-Person Participants $(n=193)$

\begin{tabular}{|c|c|c|c|c|}
\hline $\begin{array}{l}\text { Demographic and Educational } \\
\text { Characteristics }\end{array}$ & $\begin{array}{l}\text { Facebook Live Participants } \\
\qquad(n=46)\end{array}$ & $\begin{array}{l}\text { In-Person Participants } \\
\qquad(n=193)\end{array}$ & Chi-Square Test $^{a}$ & $\boldsymbol{P}$ \\
\hline \multicolumn{5}{|l|}{ Sex } \\
\hline Female & $42(91)$ & $133(69)$ & 9.50 & 0.002 \\
\hline Male & $4(9)$ & $60(31)$ & & \\
\hline \multicolumn{5}{|l|}{ Age group } \\
\hline $16-29$ & $3(6)$ & $47(25)$ & 29.56 & $<0.001$ \\
\hline $30-39$ & $8(17)$ & $24(12)$ & & \\
\hline $40-49$ & $15(33)$ & $14(17)$ & & \\
\hline$\geq 50$ & $20(44)$ & $94(49)$ & & \\
\hline Missing/not provided & - & $14(7)$ & & \\
\hline \multicolumn{5}{|l|}{ Race } \\
\hline Caucasian & $44(96)$ & $162(84)$ & 4.33 & 0.12 \\
\hline Other & $2(4)$ & $29(15)$ & & \\
\hline Missing & - & $2(1)$ & & \\
\hline \multicolumn{5}{|l|}{ Education } \\
\hline Did not complete high school & $1(2)$ & $23(12)$ & 19.19 & 0.004 \\
\hline Completed high school/GED & $14(30)$ & $59(31)$ & & \\
\hline Some college & $7(15)$ & $14(7)$ & & \\
\hline Graduated from a 2-y college & $5(11)$ & $7(4)$ & & \\
\hline Graduated from a 4-y college & $4(9)$ & $8(4)$ & & \\
\hline Postgraduate & $4(9)$ & $4(2)$ & & \\
\hline Missing/not provided & $11(24)$ & $78(40)$ & & \\
\hline
\end{tabular}

GED indicates General Educational Development (high school equivalency certificate).

Note: Values are $n(\%)$. Chi-square tests of independence were conducted to examine group differences in demographic characteristics. 
education, and sex compositions, these variables (ie, age, education, and sex) and their interactions with the delivery approach, were included in the model as control variables. All statistical analyses were conducted using SPSS (version 26, IBM Corp, Armonk, NY, 2019). The statistical significance level was set at $P<0.05$ for all analyses.

The 2 groups were statistically similar in their racial compositions but differed in terms of age, education, and sex characteristics (Table 1). The results showed a nonsignificant effect of delivery approach on FRM and diet quality gain scores, indicating that participants in both groups experienced similar levels of improvement in their FRM and diet quality (Table 2). The interaction terms (baseline score $x$ delivery approach, sex $\times$ delivery approach, education $\times$ delivery approach, and age $\times$ delivery approach) were not statistically significant. That is, participation in either delivery approach elicited similar gain scores (improvement) in FRM and diet quality (as measured by Healthy Eating Index scores) for participants.

\section{DISCUSSION AND \\ LESSONS LEARNED}

Overall, the study illustrated the potential of using Facebook Live to extend the reach of SNAP-Ed nutrition education beyond traditional audiences. Given the need for social distancing to reduce the spread of coronavirus disease 2019 in communities, SNAP-Ed implementing agencies have been advised to consider providing online nutrition education activities remotely to participants. ${ }^{10,11}$ However, implementing agencies have struggled with the means to deliver their programs virtually. For example, anecdotal information from conversations with other nutrition educators indicated a general interest in exploring Facebook Live (and other freely available social media platforms) as a tool for reaching those who are SNAP-Ed eligible. Because of the outbreak of coronavirus disease 2019 pandemic, the KYNEP has received multiple requests for implementation guidance from other universities regarding the use of Facebook Live to reach those who are SNAP-Ed eligible and participants in the Expanded Food and Nutrition Education Program during the stay-at-home restrictions (personal communications).

Findings of the outcome evaluation indicated that the face-to-face and Facebook Live approaches for delivering the HCEB curriculum elicited similar pre-post gains in participants' diet quality and FRM skills. These findings are in-line with a previous study comparing outcomes of nutrition education between face-to-face and a Webbased approach. ${ }^{12}$

Curriculum delivery through Facebook Live is not without limitations. First, Facebook Live, as an online education delivery approach, is less likely to provide learners with the same opportunities for peer interactions and engagement, collaborative learning, and discussions as face-to-face learning. ${ }^{13}$ For example, the KYNEP project implementation team observed that the interactive components of the curriculum delivery (eg, use of icebreakers) were awkward for some educators. Second, an inherent limitation to delivery through Facebook Live was that educators were unable to tell whether participants watched the entire video session. Although Facebook Live has inbuilt analytics that can tell presenters if viewers have clicked on the video (or video link), there is currently no way for presenters to know if their viewers watched the entire video or just a part of it. Third, nutrition educators vary in their degree of technological savvy. Some educators may find Facebook Live very easy to use, whereas others may experience a learning curve. Relatedly, Internet connectivity and the cost of equipment could vary across sites. Overall, commitment, personality, and willingness to embrace Facebook Live as a delivery approach are factors with the potential to influence implementation success.

Another limitation to this study was the lack of process evaluation data. Given that the educators taught both face-to-face and Facebook Live sessions, a future process evaluation will examine their perceptions of the differences and similarities between both approaches, and uncover challenges and contextual factors associated with the successful implementation of the Facebook Live

Table 2. ANCOVA Models for the Impact of Curriculum on FRM $\left(R^{2}=0.48\right)$ and Diet Quality $\left(R^{2}=0.34\right)$ with Baseline Scores, Education, Age Group, and Sex as Control Variables ( $\mathrm{N}=239)$

\begin{tabular}{|c|c|c|c|c|c|c|}
\hline \multirow[b]{2}{*}{ Independent Variables } & \multicolumn{2}{|c|}{ B Coefficient } & \multicolumn{2}{|c|}{$95 \% \mathrm{Cl}$} & \multicolumn{2}{|c|}{$\boldsymbol{P}$} \\
\hline & FRM & $\mathbf{D Q}$ & FRM & $\mathbf{D Q}$ & FRM & $\mathbf{D Q}$ \\
\hline Intercept & 21.0 & 21.4 & 11.0 to 31.0 & -9.8 to 52.6 & $<0.001$ & $<0.001$ \\
\hline Delivery approach (0 vs 1) & -3.5 & 23.5 & -13.9 to 6.8 & -9.3 to 56.2 & 0.50 & 0.15 \\
\hline Baseline score & -0.7 & -0.6 & -1.1 to -0.4 & -1.0 to -0.9 & $<0.001$ & $<0.001$ \\
\hline Sex (female vs male) & -2.5 & 0.4 & -11.0 to 6.0 & -20.0 to 20.1 & 0.48 & 0.32 \\
\hline Education & -1.1 & -0.8 & -2.1 to -0.2 & -4.5 to 2.8 & $<0.05$ & 0.77 \\
\hline Age group & -0.1 & 1.9 & -1.6 to 1.4 & -3.2 to 7.1 & 0.28 & 0.95 \\
\hline Baseline $\times$ delivery approach & 0.2 & -0.1 & -0.1 to 0.5 & -0.5 to 0.4 & 0.25 & 0.78 \\
\hline Sex $\times$ delivery approach & 1.9 & -11.6 & -6.8 to 10.6 & -33.0 to 9.8 & 0.67 & 0.28 \\
\hline Education $\times$ delivery approach & 0.4 & 1.1 & -0.8 to 1.5 & -3.2 to 5.4 & 0.53 & 0.60 \\
\hline Age group $\times$ approach & -0.6 & -3.7 & -2.2 to 1.0 & -9.4 to 2.0 & 0.43 & 0.20 \\
\hline
\end{tabular}

$\mathrm{DQ}$ indicates diet quality; FRM, food resource management skills; $\mathrm{R}^{2}$, multivariate coefficient. 
approach. Finally, the lack of a power analysis to determine how many participants needed to see a significant difference if there was one was not conducted, and the lack of significant differences may be due to too few participants.

The 21st century is undoubtedly the age of creative technological innovations, including social media platforms. Although KYNEP focused on the use of Facebook Live for delivering nutrition education, there are other alternatives (eg, Periscope, Snapchat, YouTube, etc) that could serve the same or similar purposes. ${ }^{1,3}$ Further studies are needed to explore the features of these alternatives and their appropriateness for delivering nutrition education programs to limited-resource populations.

\section{NOTES}

This evaluation study is part of the University of Kentucky's SNAP-Ed program, funded by US Department of Agriculture's Supplemental Nutrition Assistance Program. This institution is an equal opportunity provider. Kentucky SNAP-Ed data is stored and managed in the Web-based Nutrition Education Evaluation and Reporting System, a data warehouse created by the US Department of Agriculture. Access to and use of Kentucky SNAPEd evaluation data in Web-based Nutrition Education Evaluation and Reporting System for research purposes was approved by the Institutional Review Board of the University of Kentucky.

\section{SUPPLEMENTARY DATA}

Supplementary data related to this article can be found at https://doi. org/10.1016/j.jneb.2020.08.005.

\section{REFERENCES}

1. Horsman G. Reconstructing streamed video content: a case study on YouTube and Facebook Live stream content in the Chrome web browser cache. Digit Investig. 2018;26:S30-S37.

2. Johnson PT, Thomas RB, Fishman EK. Facebook Live: a free real-time interactive information platform. $\mathrm{J} \mathrm{Am}$ Coll Radiol. 2018;15:201-204.

3. Haimson OL, Tang JC.What makes live events engaging on Facebook Live, Periscope, and Snapchat. Paper presented at: 2017 CHI Conference on Human Factors in Computing Systems; May 6-11, 2017; Denver, CO. https://dl.acm.org/doi/ 10.1145/3025453.3025642. Accessed June 15, 2020

4. Adedokun OA, Plonski P, JenkinsHoward B, Cotterill D, Vail A. Healthy Choices for Every Body adult curriculum improves participants' food resource management skills and food safety practices. J Nutr Educ Behav. 2018;50:638-644.

5. Murray EK, Auld G, Baker SS, et al. Methodology for developing a new EFNEP food and physical activity behaviors questionnaire. J Nutr Educ Behav. 2017;49:777-783.e1.

6. Raper N, Perloff B, Ingwersen L, Steinfeldt L, Anand J. An overview of USDA's dietary intake data system. $J$ Food Compos Anal. 2004;17:545-555.

7. US Department of Agriculture, National Institute of Food and Agriculture.
WebNEERS: planning, evaluation, and reporting. https://nifa.usda.gov/tool/ webneers. Accessed December 9, 2019.

8. Tavakol M, Dennick R. Making sense of Cronbach's alpha. Int J Med Educ. 2011;2:53-55.

9. Guenther PM, Casavale KO, Reedy J, et al. Update of the healthy eating index: HEI-2010. J Acad Nutr Diet. 2013;113:569-580.

10. US Department of Agriculture, Food and Nutrition Service. Supplemental Nutrition Assistance Program (SNAP) questions and answers, COVID-19, Set \#2. Alexandria, VA: Food and Nutrition Service; 2020. https://fns-prod.azureedge.net/sites/default/files/resourcefiles/SNAP-COVID-QA2.pdf. Accessed July 21, 2020.

11. Center for Wellness and Nutrition. Resources for SNAP-Ed implementing agencies during COVID-19. Sacramento, CA: Public Health Institute; 2020. https://2mjt5a2emh374130j5vkxw9gwpengine.netdna-ssl.com/wp-content/ uploads/2020/05/Resources_for_SNAP_Ed_IA_s_FINAL_4_14.pdf. Accessed July $21,2020$.

12. Neuenschwander LM, Abbott A, Mobley AR. Comparison of a web-based vs in-person nutrition education program for low-income adults. I Acad Nutr Diet. 2013;113:120-126.

13. Toro-Troconis M, Alexander J, FrutosPerez M. Assessing student engagement in online programmes: using learning design and learning analytics. Int J High Educ. 2019;8:171-183.

\section{ORCID}

Omolola A. Adedokun: http://orcid. org/0000-0002-0705-2976 